\title{
Efficacy of Music Therapy on Adolescents with Depressive Symptoms
}

\author{
Abhilasha Bellapu', Michelle Hu${ }^{1}$, Nayeon Kim², Susan Chemmanoor ${ }^{2}$ and M. Cherie \\ Clark $^{\#}$
}

${ }^{1}$ Ardrey Kell High School, Charlotte, NC, USA

${ }^{2}$ Marvin Ridge High School, Waxhaw, NC, USA

\#Advisor

\section{$\underline{\text { ABSTRACT }}$}

Adolescents in the USA are experiencing increasing rates of depressive symptoms each year, resulting in a variety of emotional, social, neurological, and behavioral problems. Current traditional treatments are limited in their ability to reduce symptoms of depression. In the past few decades, music therapy has emerged as a viable treatment for depression and its comorbidities across various age groups and demographics. Music therapy is a unique form of clinical and evidence-based treatment characterized by a relationship between the music therapist and patient to address the patients' needs through various methods such as song-writing, listening, and/or singing. This literature review analyzes a wide range of qualitative and quantitative sources studying various cohorts and contexts to examine the efficacy of music therapy for treating adolescent depression in comparison to traditional treatments. We found that most sources concluded that music therapy is more effective than traditional treatments and can be used as a supplement to such treatments. Music therapy has multiple positive socio-emotional, behavioral, and neurological effects, particularly for adolescents with depressive symptoms. Furthermore, many studies noted improvements in the comorbidities and related disorders of depression. In the future, studies should be conducted with standardized trials focusing specifically on adolescents and music therapy treatments to refine therapeutic applications. In conclusion, we make the case that music therapy should be made more accessible to adolescents as a treatment option.

\section{Introduction}

\section{Background}

As rates of adolescent depression in the USA continue to rise, music therapy has become increasingly recognized as an effective treatment for depression and depressive symptoms (Mojtabai et al., 2016; Weinberger et al., 2017). Broadly speaking, the current literature in the field of music therapy contains an abundance of qualitative and quantitative studies performed in various contexts and observed through various outcomes, such as emotional, behavioral, and neurological, to demonstrate music therapy's efficacy (e.g., Aalbers et al., 2017; Albornoz, 2011; Algoodkar \& Sunitha, 2019; Chang et al., 2008; Erkkilä et al., 2011; Langhammer et al., 2019; Mohammadi et al., 2011; Popa, 2015; Raglio et al., 2015; Ramirez et al., 2018; Sharma \& Jagdev, 2012; Shiranibidabadi \& Mehryar, 2015; Wu, 2002). From its ability to improve health outcomes and the quality of life of patients diagnosed with myriad physical and psychological disorders to its ability to reduce depressive symptoms, according to the evidence from meta-analyses and systematic reviews, music therapy is accepted as a viable treatment method across the board (e.g., Aalbers et al, 2017; Kamioka et al., 2014; Leubner \& Hinterberger, 2017; Stegemann et al., 2019; Tang et al., 2020; Zhao, 2016).

Specifically, in the field of depression, music interventions have shown consistency in reducing depressive symptoms and reducing the effects of common comorbidities (e.g., Kamioka et al., 2014; Leubner \& Hinterberger, 
2017; Mohammadi et al, 2011; Porter et al., 2017; Ramirez et al., 2018). For adolescents in particular, music therapy may be a viable treatment that reduces the possible side effects of traditional pharmacological treatment and provides adolescents the opportunity to relieve their depressive symptoms by expressing themselves in creative ways (Albornoz, 2011; Porter et al., 2017; Stegemann et al., 2019).

\section{Purpose and Scope}

The purpose of this comprehensive literature review is to analyze trends and patterns and identify gaps of knowledge in the literature on the use of music therapy and music medicine for adolescents with depression or depressive symptoms. Among this age group, depression has been a prevalent and significant issue, severely threatening the mental health and livelihoods of youth, and thus, warrants the need to study this disorder and its treatments (Weinberger et al., 2017). Additionally, this review will identify logistical inconsistencies and theoretical disagreements in the included studies and determine areas that need further research and observation.

The scope of the literature discussed in this review extends approximately from the early 90s to the present day, including studies originating from outside of the USA to consider a broader context and specific demographics. This review includes studies on both music therapy and music medicine (further explained in the section "Music Therapy versus Music Medicine"), various measurement scales, diverse study designs, and both significant and null conclusions. We also included studies on traditional treatments to compare the efficacy of these treatments to that of music therapy. Despite the seemingly broad scope of our study, we determined that it was essential to include such diverse literature to fully capture the current understanding regarding the efficacy of music therapy.

\section{Sequence}

In this review, we first discuss the background of the literature to establish the context associated with depression and music therapy. Then, we analyze the efficacy of music therapy on the general population before moving on to consider a more specific cohort, adolescents. Throughout the efficacy sections, we compare the studies in terms of the types of music therapy employed, the concerns of the comorbidities of depression, the duration of the music therapy sessions, the format of music therapy sessions, and the results of the studies. We also compare the efficacy of music therapy with the efficacy of traditional treatment on patients with depressive symptoms. Moreover, the review highlights the constraints of music therapy, including critiques and limitations. Finally, we offer conclusions and recommendations for the use of music therapy to treat adolescents with depression.

\section{Adolescent Depression}

Depression is a rampant mood disorder that includes symptoms of sadness and a loss of interest in previously enjoyed activities according to the National Institute of Mental Health (2018). It can lead to a plethora of psychophysiological issues that impact daily functioning, such as reduced quality of life, diminished concentration, insomnia or hypersomnia, fatigue, and suicidal thoughts (Algoodkar \& Sunitha, 2019; Dere-Meyer et al., 2011; Dong et. al, 2019). Numerous factors could play crucial roles in the development of depression: (1) genetics, which can contribute to the inheritability of depression from parent to offspring, (2) biochemistry, which can result in varying levels of neurochemicals that add to the symptoms of depression, (3) personality, which can cause those with a negative outlook on life or low self-esteem to be predisposed to depression, and (4) environment, which can influence depression through external factors such as poverty, neglect, or abuse (American Psychiatric Association, n.d.; National Institute of Mental Health, 2018).

Though the usual onset of depression is in adulthood, adolescent depression is becoming increasingly common (The National Institute of Mental Health, 2018; Twenge, 2020). Nationally, depression rates in adolescents have 
been on an upward trend; between 2005 and 2014, Major Depressive Episodes rose from 8.7\% to $11.3 \%$ in adolescents (12-17) versus $8.8 \%$ to $9.6 \%$ in young adults (18-25) (Mojtabai et al., 2016). A 2017 survey showed that approximately 3.2 million adolescents between 12 and 17 in the United States had at least one major depressive episode, which represented $13.3 \%$ of all adolescents in the USA (The National Institute of Mental Health, 2019). This makes depression one of the most concerning medical illnesses young people face today. Depression can have significant impacts on long-term mental health as childhood and adolescent depression can lead to persistent and recurring affective disorders in young adulthood (Dunn \& Goodyer, 2006). Furthermore, suicide, the most concerning consequence of depression, has become increasingly frequent (Curtin, 2020). "Suicide is the second leading cause of death for children, adolescents, and young adults age 15-to-24-year-olds. The majority of children and adolescents who attempt suicide have a significant mental health disorder, usually depression" (American Academy of Child and Psychiatry, 2018). Thus, this life-threatening possibility further demonstrates the critical importance of analyzing potential treatments for depression.

Despite the increasing rates, more than half of adolescents with depression in the USA did not receive any form of treatment (National Institute of Mental Health, 2019). In their qualitative study, Wisdom et al. (2006) suggested that adolescents may experience pressure to "fit in" and bury their depressive symptoms to stay "normal", which indicates that a stigma surrounds depression. They found that adolescents may perceive depression as a form of weakness or illness that they do not want to be associated with, and, as a result, not seek treatment. Other factors influencing the likelihood of pursuing treatment include parental influences and beliefs, suspicion about prescribed depression medications, and confidentiality concerns (Wisdom et al., 2006). More logistical barriers include the high cost of traditional treatments and the lack of qualified healthcare professionals (Reangsing et al., 2021). In recent decades, one non-pharmaceutical treatment has become more widely recognized for its cost-effectiveness and quality of treatment, music therapy (Algoodkar \& Sunitha, 2019).

\section{Limitations in the Research on Adolescent Depression}

Many of the sources discussed in this section had a small sample size, which limited the statistical significance and generality of their results (Dunn \& Goodyer, 2006; Wisdom et al., 2006). Second, there was wide variability in the samples collected in the studies that may have made it difficult to study a particular factor or aspect of depression in isolation (Mojtabai et al., 2016; National Institute of Mental Health, 2019; Wisdom et al., 2006). Third, the studies had low-response or follow-up rates, which may lead to a lack of a strong correlation or generalizability (Dunn \& Goodyer, 2006; National Institute of Mental Health, 2019). Finally, a widely accepted limitation of these studies is the reliance on self-reports that may lead to reduced credibility and validity in the responses due to recall bias and discomfort with exposing confidential information (Dunn \& Goodyer, 2006; Mojtabai et al., 2016; National Institute of Mental Health, 2019; Wisdom et al., 2016). Additionally, some adolescents who participated in these studies may not have accurately communicated their depressive symptoms or chose not to disclose them (Wisdom et al., 2006). All of these limitations should be taken into consideration when evaluating the research regarding the background and context of adolescent depression in the USA.

\section{Traditional Treatment for Depression}

Currently, a variety of strategies is employed to treat depression, with the most popular treatments being pharmacotherapy (medication) and psychotherapy, which can be used independently or together (Mayo Clinic Staff, 2018). Pharmacotherapy treatments include antidepressants, anti-anxiety medications, or stimulants, which aim to balance neurochemicals associated with depression (National Health Service, 2018; National Institute of Mental Health, 2016). According to the National Institute of Mental Health (2016), the most commonly used pharmaceuticals are antidepressants, which have varying effects on patients. While effective for some, they may lead to adverse side effects including nausea, weight gain, diarrhea, and problems with sleep (National Institute of Mental Health, 2016). 
General psychotherapy, on the other hand, is an effective and cost-effective form of treatment that has promising effects: increasing a patient's awareness of their thoughts, helping them understand factors contributing to their depression, and increasing control in their life (American Psychological Association, 2010; Leichsenring et al., 2006). A specific type of psychotherapy, cognitive-behavioral therapy (CBT) is an evidence-based intervention that combines cognitive and behavioral interventions (Leichsenring et al., 2006; March et al., 2007). In their literature review, Leichsenring et al. (2006) described how the cognitive aspect focuses on helping patients become cognizant of their thoughts, situations, and symptoms, while the behavioral aspect aims to help patients learn how to alter their behavior according to conditioning models to address their problems. Ultimately, the authors indicated that the purpose of CBT is to allow individuals to use their learned skills to directly tackle and alleviate symptoms of their mental disorders through collaboration and interaction with a qualified therapist.

Regarding efficacy, the studies included in Leichenring et al. (2006) indicated that CBT may not be effective in alleviating depressive symptoms in the long term. Furthermore, the studies on psychotherapy did not practice universal forms of treatment (they did not use the same models); thus, efficacious results are difficult to generalize. Researchers have also demonstrated that antidepressants may not be as effective as they are often thought to be possibly even exaggerating the symptoms of depression (Moncrieff \& Kirsch, 2005; Pigott et al., 2010).

Antidepressants and CBT are the most commonly used treatments for adolescents with depression (Parquet, 2017). Axelson and Birhamer (2001) suggested that pharmacotherapy and CBT might be effective for pediatric depression and comorbid anxiety. However, Bradley et al. (2009) noted that adolescents seem to prefer psychotherapies to antidepressants, and the National Institute of Mental Health (2016) advised using medications only as a last resort for severe forms of depression if other therapies do not work. Furthermore, another disadvantage of pharmaceutical treatment is that antidepressants can increase suicidal ideations in adolescents, particularly during short-term treatment (National Institute of Mental Health, 2018).

Cook et al. (2017) described how evidence-based psychotherapies, including the most common one, CBT, have their limitations. They tend to base their protocols on controlled trials, which are not completely reflective of the individual needs of adolescents, especially those of minority groups or those with comorbidities. Moreover, they suggested that due to the scientific rigor required for this practice, some levels of evidence become unattainable, and the clinical knowledge of professionals becomes ignored. Consequently, adolescents may lack access to the most suitable form of treatment for them and feel neglected.

Taken together, while these traditional forms of treatment are efficacious to some extent in treating depression, prominent limitations of the most common ones, pharmacotherapy and psychotherapy, necessitate the consideration of an alternative option for treatment. Alternatively, music therapy has been shown to significantly reduce symptoms of major depression and alleviate the symptoms of comorbidities when used in conjunction with these traditional forms of treatment (Aalbers et al, 2017, Kamioka et al., 2014; Stegemann et al., 2019).

\section{Limitations of the Research on Traditional Treatments for Adolescent Depression}

Archer et al. (2012), Leichsenring et al. (2006), Moncrieff \& Kirsch (2005), and Pigott et al. (2010) conducted metaanalyses and/or reviews. They noted a lack of literature in their respective research areas, a considerable lack of quality in the studies, a lack of standardization in measurement methods and collection, a failure to report negative results, and a sizable amount of bias. All of these limitations should be considered when evaluating the efficacy of traditional treatments for adolescent depression.

\section{Music Therapy Treatments}

\section{Music Therapy versus Music Medicine}

In the field of music therapy research, some studies make use of a licensed music therapist, while other studies do not (e.g., Eren, 2015; Jasemi et al., 2016; Porter et al., 2016; Shuman et al., 2016). Some literature uses the term "music 
therapy" to classify the former and the term "music medicine" to classify the latter (Bradt et al., 2014; Gold et al., 2011).

Music therapy differs from music medicine in important ways. For instance, in music therapy, the therapistclient relationship is crucial to the client's progress. The therapist helps improve the client's health and attain the client's personal aspirations by forming a therapeutic relationship and addressing emotional, social, cognitive, and behavioral needs (Raglio et al., 2015). If an intervention does not have this therapist-client relationship, even if it involves other healthcare professionals, it does not qualify as music therapy, but is instead considered music medicine (Gold et al., 2011; Leubner \& Hinterberger, 2017). Furthermore, music therapy is defined as a process, where therapists are trained to improve the client's health by using music as a tool instead of as a passive intervention. Music medicine, however, does not include a "systematic therapeutic process" (Bradt et al., 2014). While music medicine does not require active interaction from the client, in a typical music therapy session, patients have the opportunity to take part through dialogue and active music-making (Rafieyan \& Ries 2007). Interestingly enough, in a meta-analysis, Bradt et al. (2014) found that there was not a significant difference in the efficacy of both treatment types, although participants tended to prefer music therapy. This suggests that music has inherent strong therapeutic qualities.

The American Music Therapy Association (AMTA) clearly defines music therapy as requiring "a credentialed professional who has completed an approved music therapy program" (American Music Therapy Association [AMTA], n.d.-a). Any intervention outside this definition would be classified as music medicine. Zanders (2018) makes an accurate comparison when addressing the dissimilarity between the two by stating, "just because going to a music concert may be therapeutic, it does not make it therapy" (p. 219). For this review, studies that use both music therapy and music medicine are included. References to both at the same time are typically referred to as "music interventions", and studies with ambiguous terminology are classified as music therapy.

\section{History of Music Therapy}

Music therapy is a clinical and evidence-based practice that draws on the theory that music can have therapeutic effects (AMTA, n.d.-a). Throughout history, music has been recognized in various cultural contexts for its rehabilitative capacity and effectiveness in addressing the various psychological, behavioral, and physiological needs of individuals, according to the AMTA (n.d.-b).

Scholars including Plato and Aristotle (AMTA, n.d.-b) recognized music as a form of healing millennia ago. Meymandi (2009) stated, "Greek physicians used flutes, lyres, and zitters to heal their patients. They used vibration to aid in digestion, treat mental disturbance, and induce sleep... Ancient Egyptians describe musical incantations for healing the sick" (p. 43). Yet, music therapy was only explicitly referred to in 1789 (AMTA, n.d.-b). More light was shed on this newly recognized field with the first record of music therapy intervention and music therapy-related experiments in the early 1800s (AMTA, n.d.-b). However, the AMTA clarifies that it was not until the mid-1900s that there was any notable development of music therapy as a professional field (n.d.-b). With the contribution of E. Thayer Gaston, often known as the "father of music therapy", and others, music therapy flourished in terms of education, funding, and popularity (AMTA, n.d.-b). In 1998, the AMTA was formed for "the advancement of education, training, professional standards, credentials, and research in support of the music therapy profession" (AMTA, n.d.-c). Since then, multitudes of studies have been conducted to better understand the efficacy of music therapy. Altogether, through centuries of development, music therapy has evolved into an effective treatment for depression.

\section{Different Types of Music Therapy}

In the field of music therapy, there are two primary types of treatment techniques: passive music therapy and active music therapy (Prakash, n.d.). Prakash states that passive music therapy, also referred to as receptive music therapy, is defined as an intervention where individuals listen to live or recorded music as a form of therapy, with no discussion or active participation. Aalbers et al. (2017) states that the purpose of passive music therapy is typically to create 
certain moods, encourage relaxation, or decrease anxiety through silent or verbal response to the music. They indicated that passive music therapy is mostly influenced by humanistic, cognitive-behavioral, or psychodynamic beliefs. In contrast, active music therapy is defined as an intervention that actively engages clients through various participatory activities, such as singing, music composition, and instrument playing (Aalbers et al., 2017). They also suggested that the purpose of active music therapy is to help patients express and ultimately better understand their thoughts and emotions, elevate their self-esteem, and reduce stress and anxiety. Passive and active music therapy are often used together in treatment to target all the needs of patients (Aalbers et al., 2017).

Neurologically, passive music therapy engages the amygdala, the thalamus, and the auditory cortex (Prakash, n.d.). In addition to these areas, active music therapy also stimulates the cerebellum, basal ganglia, and cortical motor area (Prakash, n.d.). While there is a considerable lack of literature on direct comparisons between the efficacy of active and passive music therapy, research suggests the optimal type of therapy is dependent on the individual, a statement that drives music therapy (Aalbers et al., 2017).

\section{Music Therapy with Adolescents}

Music therapy with adolescents is a more dynamic experience compared to its use with other age groups. Since adolescents undergo changes in both their physical and mental states, it is important to administer music therapy in a way that can accommodate their nature (McFerran, 2010).

The choice of music plays a significant role in capturing the attention and prompting the self-reflection of adolescents. Music that emphasizes the idea of youth culture and self-expression, such as rock and pop music, are popular genres for adolescents (Tervo, 2001). However, it is important to note that Tervo's (2001) study is relatively dated and based on adolescents in Finland, which may not completely reflect the preferences of adolescents in the USA. In fact, recent data suggests that among adolescents between 16 and 19 in the USA, pop and hip hop are the most popular music genres (Statista Research Department, 2021). Regardless, the choice of music is essential in helping the music therapist fully understand the individuality of each adolescent, their connection to and preference for certain types of music, and the cultural and social context that they function in to better tailor their music therapy experience and address their needs (Halverson-Ramos et al., 2019).

In addition to the type of music, there are other considerations as well. Practically speaking, music therapy sessions for adolescents should be routine, long-term, and rigorous to ensure beneficial outcomes and establish a stable connection with the adolescent (Tervo, 2001). It is also suggested that music therapy should be performed in group sessions to encourage and bolster social connections between adolescents and their peers (Halverson-Ramos et al., 2019). Furthermore, adolescents may be defensive at first when it comes to intervention. Therefore, tremendous attention, support, and praise from the music therapist and others are one of the most instrumental aspects in bringing out energy within the adolescent (McFerran, 2010).

Finally, a significant difference between music therapy with adolescents and other age groups is the purpose of music therapy for each individual. With adolescents, music therapy intervention often addresses goals related to self-regulation, coping skills, self-expression, and social interaction on top of treating the adolescent's specific problem (Halverson-Ramos et al., 2019). The common techniques in music therapy used to address these goals are listening to music, lyrical analysis, musical re-creation, improvisation, and songwriting. These tools of music therapy can improve mental and behavioral problems in adolescents across various empirical studies (e.g., Albornoz, 2011; Hendricks et al., 1999; Porter et al., 2017; Shuman et al., 2016).

\section{Efficacy of Music Therapy}

Music therapy can be a suitable option for quality care, regardless of context (Wakim, et al., 2010). The literature extensively demonstrates the efficacy of music therapy in the "diminishing of pain, agitation, disruptive behavior, depression and improving communication and quality of life" across various populations and contexts (Popa, 2015, 
p. 1062). For example, Gutgsell et al. (2013) show that music therapy can significantly reduce pain in palliative care patients. Aalbers et al., (2017) demonstrate that music therapy can effectively treat depression. Lim et al. (2013) and Thaut et al. (2009) indicate that music medicine and therapy respectively can help develop language and speech ability in stroke patients and traumatic brain injury patients. Music interventions have also contributed to the improvement of global, social, cognitive, and behavioral functioning in severe cognitive and neurological disorders including, but not limited to depression, anxiety, dementia, schizophrenia, sleeping disorders, autism, stroke, multiple sclerosis, Parkinson's Disease, and Alzheimer's (Kamioka et al., 2014; Khyzhna \& Shafranska, 2020; Leggieri et al., 2019; Mahdipour \& Nematollahi, 2012; Matthews, 2015; Raglio et al., 2015). Music therapy has been well received by most patients in several circumstances and has no known harmful repercussions (Kamioka et al., 2014). However, in their meta-analyses, Aalbers et al. (2017), Kamioka et al. (2014), Leggieri et al. (2019), discussed how the lack of studies led to insufficient data and how the lack of standardization in the methods in the studies they included led to the lack of generalizability of the results to a larger population. These challenges they describe are unfortunately a prevalent issue across the field of music therapy that, to some extent, compromises the evidence of music therapy's efficacy.

\section{Cost-Effectiveness of Music Therapy}

The cost-effectiveness of virtually any treatment should be considered as a factor of its overall efficacy; if the patient cannot afford it, then it is not of value to that patient. Though research is relatively scarce regarding the cost-effectiveness of music therapy for adolescents with depressive symptoms, there are data from other populations that suggests that music therapy is an economical treatment. In a cost-benefit ratio analysis of a small sample of hospice care patients, Romo \& Gifford (2007), found that "the total cost of patients in music therapy was $\$ 10,659$ and $\$ 13,643$ for traditional care patients, resulting in a cost savings of $\$ 2984$. The music therapy program cost $\$ 3615$, yielding a costbenefit ratio of 0.83 . When using cost per patient day, the cost-benefit ratio is 0.95 " (p. 353). This analysis clearly shows significant cost reductions in using music therapy as opposed to traditional treatment despite being difficult to generalize due to the small sample size. Furthermore, after conducting empirical studies on patients diagnosed with cancer and depression, Jasemi et al. (2016) and Algoodkar and Sunitha (2019) claimed that music therapy is an inexpensive and simple treatment method - though they do not offer much detail. Despite the limited evidence to support this, the existing research and findings in the field indicate that music is financially beneficial to patients compared with other treatment types.

\section{Efficacy of Music Therapy on Depression}

A plethora of studies regarding music therapy focuses on its efficacy in improving mood disorders such as depression. The majority of studies reviewed indicate that music therapy and music medicine are effective in ameliorating depressive symptoms and improving overall quality of life (Raglio et al., 2015). In a variety of cohorts, including heart surgery patients, older adults, substance abusers, adolescents with psychiatric disorders, terminally-ill cancer patients, and depressed women, music therapy has been proven to be beneficial in elevating mood and emotional states or alleviating depressive symptoms (Albornoz, 2011; Hamid \& Biat, 2019; Mahdipour \& Nematollahi, 2012; Ramirez et al., 2018; Shuman et al. 2016; Zhao et al., 2016). For nursing home residents, music therapy has been shown to play a crucial role in the cultivation of an encouraging and stimulating environment to catalyze improvements in emotional well-being (Mohammadi et al., 2011). For heart surgery patients, music therapy creates a soothing environment which can lead to a decrease in depression-related comorbidities such as stress and anxiety (Mahdipour \& Nematollahi, 2012). Leubner and Hinterberger (2017) concluded in their meta-analysis that across multiple age groups, music therapy could improve quality of life and decrease symptoms of depression. Logistically speaking, Jasemi et al. (2016) suggested that music therapy is a cost-effective, convenient, and reliable form of treatment for both depression and its comorbidity, anxiety. However, it was unclear whether their study examined music therapy or music medicine. Regardless, music therapy overall demonstrates its efficacy both in terms of the treatment and logistics. 


\section{Neurological Effects}

Although music therapy has demonstrated significant efficacy in improving external behavioral and observable emotional changes, understanding the mechanisms that music therapy arouses within the brain is also crucial to gaining a full comprehension of the viability of this treatment. Breakthroughs in the past few decades have shown that the brain is characterized by plasticity, or the ability to restructure synaptic connections due to environmental and internal factors (Raglio et al., 2015). In certain instances, this may lead to the development of neurological disorders including depression. Over the years, studies on music intervention have shown efficacy from neurochemical, psychological, and rehabilitative standpoints to improve some of these neurological disorders (Raglio et al., 2015). From a neurochemical standpoint, music stimulates almost all limbic and paralimbic structures that regulate emotion (amygdala, hippocampus, nucleus accumbens, etc.) which may act atypically in patients diagnosed with depression (Koelsch, 2010; Koelsch, 2014; Raglio et al., 2015). From a psychological standpoint, music, particularly active music therapy, engages various social areas in the brain that strengthen interaction, relationships, and social solidarity. Lastly, from a rehabilitative standpoint, music induces the proper functioning and regulation of motor areas in the brain, which then results in contentment and positive mood in patients.

Music's aptness in engaging the brain has been shown to improve patients' social, neurological, motor, cognitive, and emotional skills (Raglio et al., 2015). In a study where participants listened to rock music for 23 minutes, the researchers noted that the right lateral EEG activity was minimized for female adolescent patients diagnosed with chronic depression (Field et al., 1998). Since high levels of right lateral EEG activity are associated with negative mood and emotions, the study reveals the notable efficacy of music interventions for reducing depressive symptoms. Even though the authors noted that the visible and self-reported mood of the patients at the end of the treatment did not change, the EEG results indicated that music therapy reduced the neurological effects of depression. In sum, the neurological perspective adds more concrete evidence to the claim that music therapy is effective.

\section{Socioemotional Effects}

Music therapy is a form of psychotherapy that brings meaning to life by creating an artistic experience. This psychotherapeutic treatment can allow the participant to make strides towards behaving and thinking in a new way as a result of getting satisfaction from their music therapy sessions. In addition, music therapy has been shown to improve aspects relating to mood including emotional communication, self-assurance, and interpersonal skills (Raglio et al., 2015). Specifically for elderly cohorts, according to Mohammadi et al. (2011), music therapy can act as an instrument for emotional catharsis, and subsequently allow them to cope with depression. Two separate studies, an EEG-based analysis on palliative care patients and a semi-experiment on depressed women note that music therapy or medicine respectively can increase positive emotions such as happiness (Hamid \& Biat, 2019; Ramirez et al., 2018). This is likely because music can "induce strong emotions," particularly positive emotions (Ramirez et al., 2018, para. 1).

Music therapy can improve social skills as well by directly influencing personality and emotions without first being processed by cognition (Eren, 2015). Active music therapy particularly, allows patients, regardless of age, to express their emotions, develop a deeper understanding of their emotional and socio-emotional issues, and strengthen their emotional competencies (Aalbers et al., 2017). The active techniques use a variety of musical activities, such as musical improvisation or composition, to build a musical bond between the therapist and patient as they communicate. Passive techniques involve the patient listening or inactively responding to music to stimulate certain moods and emotions, induce relaxation and reflection, or reduce stress and anxiety. Therefore, music therapy has strong positive effects on socioemotional functioning.

\section{Behavioral Effects}


Symptoms of depression are often very nuanced, individualized, and difficult to differentiate from sadness (Maj, 2011). However, recognizable symptoms include anxiety (one of the most pronounced comorbidities that is discussed later), aggression and anger, insomnia, reduced self-esteem, and the development of eating disorders (Mayo Clinic Staff, 2018). Music therapy has demonstrated efficacy in alleviating the various symptoms and comorbidities of depression by positively influencing individuals in ways that benefit both their physical and emotional well-being. For specific cohorts such as dementia patients and pregnant women, music therapy has been shown to reduce anxiety, irritability, aggression, and stress (Chang et al., 2008; Langhammer et al., 2019). In addition to reductions in anxiety and stress, Hwang and Oh (2013) found that music therapy reduced anger in alcoholic-dependent participants with depression. Hakvoort et al. (2013) showed that music therapy enhanced anger management skills and eliminated aggressive behaviors in forensic psychiatric patients. Choi et al. (2010) also noted that the use of music therapy is correlated with both a significant decrease in aggression and an increase in self-esteem for aggressive children. Other studies point to the effectiveness of music interventions in promoting self-esteem in young adults with depression and stressed adolescents (Sharma \& Jagdev, 2012; Wu, 2002). Chen et al. (2015) determined that for male prisoners, improvements in self-esteem in addition to reductions in depression and anxiety were most prominent among the younger population, thus supporting the substantial effect music therapy can have for adolescents with depression. Several researchers, largely using meta-analyses, identified passive music therapy and music medicine, particularly listening to calming music, as a useful tool in improving sleep quality and minimizing insomnia symptoms (Amiri et al., 2019; Chang et al., 2008; Feng et al., 2018; Harmat et al., 2008; Jespersen et al., 2015; Levin, 1998; Wang et al., 2014). Finally, Pasiali et al. (2020) and Bibb et al. (2015), concluded that music therapy reduced anxiety and helped with self-esteem problems among individuals with eating disorders. Lejonclou and Trondalen (2009) suggested that this is likely a result of the musical experience allowing participants to express their inner selves free of shame. As Leubner and Hinterberger's (2017) meta-analysis concisely confirmed, music interventions have beneficial effects that improve self-esteem, confidence, motivation, anxiety, and sleep concerns. Overall, the myriad benefits that music therapy is capable of when addressing the behavioral effects of depression are significant.

\section{Efficacy of Different Therapies to Improve Depression}

According to corroborating studies across different contexts, music therapy is highly effective when used in conjunction with traditional treatments such as pharmacotherapy. Music therapy has a greater effect on reducing depressive symptoms than traditional treatment alone (Aalbers et al., 2017; Erkkilä et al., 2011; Shiranibidabadi \& Mehryar, 2015). In some cases, the combination of music therapy (or music medicine) and traditional treatment has also been shown to reduce anxiety, a common comorbidity of depression (Erkkilä et al., 2011; Shiranibidabadi \& Mehryar, 2015).

Concerning music therapy types, active and passive music therapy differ in fundamental ways. However, corroborating evidence shows that their effect on depression is similar (Aalbers et al., 2017). Active music therapy, specifically improvisational music therapy, has been shown to have a clinically significant effect on reducing clinical depression for substance abusers (Albornoz, 2011). Engaging with music in the form of dancing, clapping, or playing an instrument has also been shown to improve motor function, regulation, and feelings of self-control (Ghasemtabar et al., 2015). This additional engagement with music during therapy sessions can improve the rehabilitative process by promoting emotional regulation (Mohammadi et al., 2011; Raglio et al., 2015). However, some researchers observed that active music participation could cause high initial anxiety, likely because participants may at first feel uncomfortable and embarrassed about engaging in music-making methods (Carr et al., 2017). Therefore, it is crucial for music therapists to provide support and meet individual needs while employing active music therapy. Passive, or receptive, music therapy has also been shown to reduce depressive symptoms. Even though it may produce a quicker response from the patient, the effect may be less potent than that of active music therapy (Atiwannapat et al., 2016). 
In other words, passive music therapy may work faster, but active music therapy has a more significant therapeutic effect (Atiwannapat et al., 2016).

\section{Treating Anxiety as a Comorbidity of Depression}

Anxiety is a prevalent comorbidity of depression in which an individual is triggered in response to a perceived threat (Leubner \& Hinterberger, 2017). Thus, it is pertinent to examine the efficacy of music therapy as a treatment for anxiety. Leubner and Hinterberger (2017) suggest in their meta-analysis that music therapy is associated with alleviated symptoms of anxiety, though they express concern that the studies included in their meta-analysis did not have a standard interpretation of "anxiety disorders." Similarly, Aalbers et al. (2017) conducted a meta-analysis and determined that music therapy used in parallel with traditional care significantly reduced anxiety symptoms, although the findings were of low quality. Across various cohorts, music therapy has demonstrated effectiveness in alleviating anxiety as a comorbidity of depression. For adult and adolescent substance abusers, music therapy, along with traditional treatment, has demonstrated efficacy in reducing anxiety as a depressive symptom (Albornoz, 2011). For nursing home residents, after 10 weeks of music therapy, results show that anxiety and depression were both significantly reduced (Mohammadi et al., 2011). Cancer patients also experienced a significant decrease in both depression and anxiety following music medicine sessions (Jasemi et al., 2016). Music therapy also reduced both anxiety and depression as comorbidities of obsessive-compulsive disorders (Shiranibidabadi and Mehryar, 2015). Finally, Erkkilä et al. (2011) find that music therapy accompanying traditional treatment is more effective than traditional treatment alone in alleviating anxiety symptoms in adults with depression.

\section{Efficacy Regarding Practice Elements of Music Therapy as a Treatment for Depression}

\section{Duration}

Much of the literature on using music therapy to treat depression examined treatments that were 8 weeks long or had 12 therapy sessions (Algoodkar \& Sunitha, 2019; Atiwannapat et al., 2016; Castillo-Pérez et al., 2010; Chen, 1992; Hanser \& Thompson, 1994; Hendricks et al., 1999; Leubner \& Hinterberger, 2017). Tang et al. (2020) suggest that shorter and medium-length treatment periods between 1 to 12 weeks may be more effective than longer interventions, thus, most studies fall into the ideal range. The length of each session was approximately 1 hour long (Algoodkar \& Sunitha, 2019; Atiwannapat et al., 2016; Chen, 1992; Erkkilä et al., 2011; Hanser \& Thompson, 1994; Hendricks, 2001; Leubner \& Hinterberger, 2017; Zerhusen et al., 1991). However, some of the studies varied in length and duration, while still falling within the 30 minutes to 2-hour duration (Albornoz, 2011; Atiwannipat, 2016; Harmat et al., 2008; Hendricks, 2001; Jasemi et al., 2016; Mohammadi et al., 2011; Radulovic, 1996; Ramirez et al., 2018).

\section{Individual vs Group Sessions}

Both individual and group music interventions provide patients with appropriate environments to alleviate depressive symptoms. Leubner and Hinterberger (2017) found no significant differences between the therapeutic formats. Studies have found that individual music therapy in addition to traditional care is effective in ameliorating depressive symptoms (Erkkilä et al., 2011; Ramirez et al., 2018). Furthermore, individual music therapy effectively complements traditional care when regularly used to improve participants' motivation. (Gold et al., 2013; Leuber \& Hinterberger, 2017; Wheeler et al., 2003). Group sessions, on the other hand, center on social interaction and improving interpersonal skills (Leubner \& Hinterberger, 2017). Research demonstrates that group music therapy can improve individuals' communication, social skills, and self-expression (Leubner and Hinterberger, 2017; Shuman et al., 2016; Wheeler et al. 2003). Moreover, Chu et al., (2014) point to the practicality of using group therapy as an unobtrusive and costeffective form of treatment for depressed older adults with dementia. However, when comparing individual and group 
music intervention, it appears that individual music therapy is a more effective treatment format because of the increased intimacy and individualization of the intervention (Aalbers et al., 2017).

\section{Limitations of the Literature on Efficacy of Music Therapy to Treat Depression}

Certain limitations warrant a statement here when drawing conclusions about the efficacy of music therapy on depression. For instance, most studies mentioned above conclusively agree that more methodological rigor, larger samplesizes, representative demographics, high-quality trials evaluating efficacy, long-term observations, and in general, accounting and testing for more variables should be factored into future studies (Albornoz, 2011; Algoodkar \& Sunitha, 2019; Amiri et al., 2019; Atiwannapat et al., 2016; Bibb et al., 2015; Carr et. al., 2017; Chu et. al., 2014; Jasemi et al., 2016; Leubner \& Hinterberger, 2017; Mohammadi et al., 2011; Raglio et al, 2015.; Shiranibidabadi \& Mehryar, 2015; Shuman et al., 2016; Wheeler et. al., 2003; Zhao et al., 2016). Particularly, when discussing the overall efficacy of music therapy, we must be careful in concluding that many different cohorts of people benefit from music therapy. Although the effects were generally positive, effectiveness varied based on the individual (Shuman et al., 2016; Leubner \& Hinterberger, 2017). Several studies also expressed concern over the lack of statistically significant differences when measuring the efficacy of music therapy (Chang et al., 2008; Hwang \& Oh, 2013; Wang et al., 2014). Another concern is the inconsistency in studies regarding the presence (or lack thereof) of a licensed music therapist. This section includes studies that utilize both music medicine and music therapy (e.g., Jasemi et al., 2016; Algoodkar \& Sunitha, 2019). Finally, all studies in this section possessed a lack of blinding for participants due to the nature of music therapy as an intervention.

\section{Efficacy of Music Therapy on Adolescents with Depressive Symptoms}

Music therapy can be considered a safe and effective intervention in alleviating symptoms and enhancing well-being in children and adolescents. Specifically, researchers have found that both music therapy and music medicine reduce depressive symptoms in children and adolescents with behavioral and emotional problems, including depression (Geipel et al., 2018; Naylor et al, 2010; Parquet, 2017; Porter et al., 2017; Rahmani et al., 2016; Shuman et al. 2016; Stegemann et al., 2019). Positive effects indicating improvement in motivational and emotional competencies of people with depression were also observed (Hendricks et al., 1999; Porter et al., 2017; Stegemann et al., 2019). Adolescents experienced significant increases in hope and subjective happiness with music therapy intervention (Hendricks et al. 1999; Kwok, 2018). Additionally, Hendrick et al. (1999) conducted a study on the effectiveness of music therapy on high school students and suggested that group music interventions were significantly more effective than cognitivebehavioral therapy. It is also important to note that according to Stegemann et al. (2019), almost none of the systematic reviews concerning music therapy have reported any harmful effects of music therapy on adolescents.

\section{Emotional and Behavioral Effects}

Music therapy and music medicine give adolescents with depressive symptoms the opportunity to improve their quality of life and socialization in addition to reducing depressive symptoms and anxiety (Hendricks et al.,1999; Porter et al., 2017; Stegemann et al., 2019). For instance, Shuman et al. (2016) have documented mood improvements in adolescents in a spectrum of psychiatric disorders through music therapy. More specifically, Stegemann et al. (2019) indicated that music interventions improved adolescents' mood recognition, regulation, and awareness, which suggests that it can help adolescents perceive their depressive state and take conscious steps to alleviate it. Hendricks et al. (1999) added that music therapy fosters positive emotions in adolescents with depressive symptoms, thus, combating the negative emotions and mood states associated with depression. Furthermore, researchers have identified music medicine as a successful means of improving self-esteem, whether for adolescents with depression or general emotional disturbances (Sharma \& Jagdev, 2012). However, Porter et al. (2017) noted that the effects of their study were temporary and minimal, meaning the results are not decisive enough to warrant major changes in the field (Porter et 
al., 2017; Sharma \& Jagdev, 2012). Given the evidence, music therapy and medicine can be assumed to be effective in creating a positive experience for adolescents.

In addition to increasing positive effects, music therapy reduced the negative consequences of depressive symptoms. Geipel et al. (2018) suggested that music-based interventions decrease internalizing symptoms in children and adolescents. These are symptoms that are typically not expressed outwardly but stem from depression and anxiety (Brumariu \& Kerns, 2010). Naylor et al. (2010) found that adolescents suffering from grief, which possesses certain similarities to depression, experienced a reduction in internalizing symptoms related to coping through music medicine, although this was not consistent across all measurement tools. Regarding behavioral effects, they added that music interventions correlate with a decrease in problematic behavior associated with grief and distress. Hilliard (2007) identified similar results, finding that children with grief were alleviated of symptoms to some extent through music therapy; symptoms include withdrawal, disruptive behavior, distress, physiological effects, poor academic performance, mood or behavior swings, and emotional problems.

\section{Music Therapy Compared to Traditional Treatment for Adolescents with Depressive Symptoms}

The efficacy of music interventions is comparable to that of traditional forms of treatment for depression, including pharmacotherapy, collaborative care, occupational therapy, electric-convulsive therapy (ECT), hospitalization, and psychotherapy, and can be used in conjunction with them to effectively alleviate depressive symptoms across all age groups (Aalbers et al., 2017; Mayo Clinic Staff, 2018). Hendricks et al. (1999) suggested that music therapy may be more effective than traditional treatments in reducing depressive symptoms in adolescents. Rahmani et al. (2016) came to the same conclusion using music and art therapy for Iranian adolescent girls with depression. Instead of suggesting that music therapy can be used independently as a substitute for traditional treatment, many propose that music therapy and medicine enhances the outcomes of traditional treatment when used in conjunction (Aalbers et al., 2017; Albornoz, 2011; Porter et al., 2017; Stegemann et al., 2019). This is likely because music therapy adds a positive, interactive form of treatment that can elevate the mood of adolescents suffering from depression while minimizing the negative side effects of traditional treatments.

\section{Limitations of the Literature on the Efficacy of MT on Adolescents with Depressive Symptoms}

Several limitations were common among the studies and should be noted. First, most studies used a self-reported measurement, which can reduce the reliability of the results and introduce possible participant bias (Hendricks, 1999; Parquet, 2017; Porter et al., 2017; Rahmani et al., 2016; Sharma \& Jagdev, 2012). Second, there were problems with the samples of numerous studies, including small sample sizes and samples containing participants of a specific geographic location or demographic (Erkkilä et al., 2011; Hendricks et al., 1999; Hilliard, 2007; Kwok, 2018; Parquet, 2017; Porter et al., 2017; Rahmani et al., 2016; Sharma \& Jagdev, 2012; Stegemann et al., 2019). We believe that these limitations with the samples may lead to difficulty in the ability to generalize the results of the studies. Third, there was a significant lack of standardization among the studies in their definitions of music therapy and depression, in measures, and in methodology (Aalbers et al., 2017; Geipel et al., 2018; Hendricks et al., 1999; Kwok, 2018; Naylor et al., 2010; Parquet, 2017; Shuman et al., 2016). Lastly, some studies deviate from the focus of our review, such as not addressing the adolescent population or depression specifically but were important to include (e.g., Aalbers et al., 2017; Hilliard, 2007; Naylor et al., 2010; Sharma \& Jagdev, 2012; Shuman et al., 2016; Stegemann et al., 2019;). Many studies conducted their review on a wide range of physical and mental illnesses, which made it difficult to consider whether a study's effectiveness specifically applies to depression. In response to some of these limitations, several authors critiqued themselves and provided implications for future studies based on the lacking aspects of their studies, such as the need for more studies in inclusive music settings (Porter et al., 2017; Stegemann et al., 2019).

\section{Conclusion}


Throughout this comprehensive review, we analyzed the literature on music therapy in several contexts to assess the effectiveness of this treatment modality for depressive symptoms, particularly in adolescents. Overall, the existing body of literature on music therapy contributes an expansive range of qualitative and quantitative studies investigating music therapy's effectiveness in treating depressive symptoms and common comorbidities. This range included studies with varied participant demographics, depressive symptoms and comorbidities, measurement scales, treatment formats, study methods, clinical beliefs, and conclusions.

Regarding demographics, despite an attempt to focus on studies that originated from the USA, we realized that there was not enough USA-based research in this area to address our inquiry fully. Thus, we included many studies originating from other countries (e.g., Algoodkar \& Sunitha, 2019; Atiwannapat et al., 2016; Chen, 1992; Erkkilä et al., 2011; Hakvoort et al., 2013; Hamid \& Biat, 2019; Jasemi et al., 2016; Kwok, 2018; Leubner \& Hinterberger, 2017; Mohammadi et al., 2011; Porter et al., 2017; Rahmani et al., 2016; Sharma \& Jagdev, 2012; Stegemann et al., 2019).

In our review, some researchers studied the improvement of the symptoms of depression to examine music therapy and music medicine's efficacy. Others studied the improvement of comorbidities and related disorders of depression either in conjunction with or independent from depression (e.g., anxiety, anger and aggression, substance abuse disorders, grief, obsessive-compulsive disorder, internalizing symptoms, and eating disorders) (e.g., Aalbers et al., 2017; Albornoz, 2011; Bibb et al., 2015; Chang et al., 2008; Erkkilä et al., 2011; Geipel et al., 2018; Hakvoort et al., 2013; Hendricks et al., 1999; Leubner \& Hinterberger, 2017; Mohammadi et al., 2011; Naylor et al., 2010; Shiranibidabadi \& Mehryar, 2015; Stegemann et al., 2019). For example, Algoodkar and Sunitha (2019) solely studied the positive effects music medicine has on alleviating depressive symptoms with almost no reference to comorbidities. On the contrary, Shiranibidabadi and Mehryar (2015) investigated music medicine as a potential treatment for a trio of comorbid disorders: obsessive-compulsive disorder, anxiety, and depression.

Regarding measures represented in the studies reviewed, there was wide usage of multiple self-report scales, which varied on a study-by-study basis. The literature also included meta-analyses, literature reviews, empirical research, academic texts, and other formats.

Some studies used only passive music therapy or active music therapy while others incorporated both into the treatments offered to participants. Additionally, the research community was divided on whether or not music therapy requires the presence of a professional music therapist. Researchers including Jasemi et al. (2016) and Hamid and Biat (2019) disregarded the need for a music therapist whereas researchers including Hendricks et al. (1999) and Aalbers et al. (2017) strictly defined music therapy as requiring a qualified therapist. Some researchers, in an effort to provide comprehensive information, recognized the discrepancy between music therapy and music medicine, but still included both in their reviews or analyses (Kamioka et al., 2014; Leubner \& Hinterberger, 2017; Naylor et al., 2010; Raglio et al. 2015; Stegemann et al., 2019; Tang et al., 2020). Furthermore, the definition of depression depended on the researchers. Some studied participants with "depressive symptoms" based on different evaluative scales (e.g., The Beck Depression Inventory, the HAM-A, the MADRS), while others studied patients diagnosed with Major Depressive Disorder.

Among the literature included in this review, several authors concluded that music therapy is an efficacious supplement to traditional treatment (e.g., medication, psychotherapy) rather than a replacement thereof for reducing depressive symptoms and increasing overall well-being (Aalbers et al., 2017; Albornoz, 2011; Atiwannipat, 2016; Erkkilä et al., 2011; Porter et al., 2017; Shiranibidabadi and Mehryar, 2015, Stegemann et al., 2019). In short, despite the overall limitations seen in the literature, our consensus is that music therapy is an effective treatment option for reducing depressive symptoms in adolescents.

\section{Limitations}


While this review is comprehensive, several overall limitations should be considered. First, a lack of standardization in the methods, measures, and definitions was a consistent concern in much of the reviewed literature. A major inconsistency was the definition of what qualified as music therapy. Many researchers also expressed concerns over their studies' short durations and suggested the need for observation of long-term effects of music therapy (e.g., Mohammadi et al., 2011; Porter et al., 2017 ). Furthermore, while some researchers included extremely homogenous groups (e.g., similar age, culture, gender, and depressive symptoms), others studied a broad range of diverse demographics, creating difficulties for us in drawing generalizable and reliable conclusions. In some cases, studies did not directly relate to our thesis (i.e., studies not solely focused on depression) but possessed important information relevant to our inquiry that ultimately led us to include them in our review (e.g., Geipel et al., 2018; Ghasemtabar et al., 2015; Khyzhna \& Shafranska, 2020). Overall, we found that there was a lack of research on the efficacy of music therapy on adolescents with depressive symptoms.

Regarding the literature's consensus, while the majority of studies concurred that music therapy is efficacious; some studies acknowledged that there were nonsignificant results and/or negative results (e.g., Leubner \& Hinterberger, 2017). These instances of non-uniformity garnered a concern for a decisive conclusion regarding the effectiveness of MT. Second, researcher and participant bias was present in the majority of the studies reviewed due to a lack of blinding, unrepresentative samples, and self-reported results. Third, small sample sizes were a recurring issue as they contributed to the lack of generalizability (e.g., Albornoz, 2011; Hendricks et al., 1999; Mohammadi et al., 2011; Rahmani et al., 2016). Lastly, we observed an inherent problem in the research of music therapy: while research demands standardized measurement scales and therapeutic processes, music therapy demands flexibility to address individual client needs appropriately.

\section{Future Research}

Future research should aim to conduct more standardized trials focused on the use of music therapy specifically for adolescents with depressive symptoms without the inclusion of comorbidities (e.g., anxiety, pregnancy, substance abuse, OCD, etc.) to directly investigate the link between depression and music therapy in this cohort. There should be a universal system of standards for defining music therapy, measuring depressive symptoms, and having larger and randomized samples. Furthermore, the cost-effectiveness of music therapy as a treatment should be directly compared to traditional treatments, such as pharmacotherapy and psychotherapy to confirm or refute the effectiveness of using music therapy in monetary terms. Finally, more studies focusing on the efficacy of music therapy alone versus music therapy in conjunction with traditional treatments should be conducted to explicitly compare the efficacy of both.

\section{Implications}

Our review of music therapy and its efficacy in adolescents with depressive symptoms provides a fuller picture of the current research in this area, tying together a multitude of studies with various implications. Based on our findings, music therapy can indeed be used as a viable treatment option and should, therefore, be actively implemented for adolescent depression. Since adolescents today are heavily influenced by music and listen to it frequently, the availability of a music therapist could give them access to a more desirable and suitable form of treatment (Council on Communications and Media, 2009). Throughout this literature review, we asserted that music therapy is an evidencebased practice and can be implemented in many contexts, particularly school systems, in hopes of treating adolescents. Currently, counseling programs seen in schools are generally traditional in their approaches to therapy. Implementing music therapy programs that work in tandem with existing counseling programs in schools would be beneficial for students experiencing depressive symptoms (Swanson, 2020). Music therapy has been proven cost-effective, so it would not be detrimental to implement in schools (Romo \& Gifford, 2007). Outside of school, music therapy should be promoted as a potential ancillary treatment option for medical professionals (e.g., psychologists, psychiatrists) to 
use when treating their adolescent patients with the assistance or direction of a professional music therapist. Moreover, music therapy programs can be created within medical facilities to engage adolescents and effectively treat depressive symptoms and other comorbidities. These suggested actions would help to establish music therapy as a practical and ubiquitous method to treat depression and depressive symptoms. In closing, music therapy can be considered an efficacious supplement and/or alternative for treating general and adolescent depression and should continue to be studied and implemented.

\section{Acknowledgments}

We would like to thank our advisor Dr. M. Cherie Clark for guiding us in this project.

\section{References}

Aalbers, S., Fusar-Poli, L., Freeman, R. E., Spreen, M., Ket, J. C., Vink, A. C., Maratos, A., Crawford, M., Chen, X. J., \& Gold, C. (2017). Music therapy for depression. The Cochrane Database of Systematic Reviews, 11(11), CD004517. https://doi.org/10.1002/14651858.CD004517.pub3

Abramowitz, J. S., Taylor, S., \& McKay, D. (2005). Potentials and limitations of cognitive treatments for obsessivecompulsive disorder. Cognitive Behaviour Therapy, 34(3), 140-147. https://doi.org/10.1080/16506070510041202

Albornoz, Y. (2011). The effects of group improvisational music therapy on depression in adolescents and adults with substance abuse: a randomised controlled trial. Nordic Journal of Music Therapy, 20(3), 208-224. https://doi.org/10.1080/08098131.2010.522717

Algoodkar, S., \& Sunitha, G. (2019). Impact of music therapy in reducing the severity of depression measured by MADRS among depression patients: A randomized control study. International Archives of Integrated Medicine, 6(1), 41-47, http://oaji.net/articles/2019/1398-1548401765.pdf

American Academy of Child and Adolescent Psychiatry. (2018, June). Suicide in children and teens. https://www.aacap.org/AACAP/Families and Youth/Facts for Families/FFF-Guide/Teen-Suicide-010.aspx

American Music Therapy Association. (n.d.-a). What is music therapy? Retrieved 25 September, 2021, from https://www.musictherapy.org/about/musictherapy/

American Music Therapy Association. (n.d.-b). History of music therapy. Retrieved 5 August, 2021, from https://www.musictherapy.org/about/history/

American Music Therapy Association. (n.d.-c). What is AMTA? Retrieved 25 September, 2021, from https://www.musictherapy.org/about/whatis/

American Psychiatric Association. What is depression? Retrieved 26 September, 2021, from https://www.psychiatry.org/patients-families/depression/what-is-depression

American Psychological Association. (2010). Depression and how psychotherapy and other treatments can help people recover. https://www.apa.org/topics/depression/recover 
Amiri, S., Parvizi Fard, A., Khaledi-Paveh, B., Foroughi, A., Bavafa, A., Bazani, M., Mohammadian, Y., \& Sadeghi, K. (2019). The effectiveness of music therapy on insomnia using Persian traditional music. Journal of Kermanshah University of Medical Sciences, 23(2). https://doi.org/10.5812/jkums.86914

Archer, J., Bower, P., Gilbody, S., Lovell, K., Richards, D., Gask, L., Dickens, C., \& Coventry, P. (2012). Collaborative care for depression and anxiety problems. Cochrane Database of Systematic Reviews, (10). https://doi.org/10.1002/14651858.CD006525.pub2

Atiwannapat, P., Thaipisuttikula, P., Poopityastaporn, P., Katekaew, W. (2016). Active versus receptive group music therapy for major depressive disorder-A pilot study. Complementary Therapies in Medicine, 26, 141-145. https://doi.org/10.1016/j.ctim.2016.03.015

Axelson, D. A., \& Birmaher, B. (2001). Relation between anxiety and depressive disorders in childhood and adolescence. [Abstract] Depression and Anxiety, 14(2), 67-78. https://doi.org/10.1002/da.1048

Bibb, J., Castle, D., \& Newton, R. (2015). The role of music therapy in reducing post meal related anxiety for patients with anorexia nervosa. Journal of Eating Disorders, 3(1). https://doi.org/10.1186/s40337-015-0088-5

Bradley, K. L., McGrath, P. J., Brannen, C. L., \& Bagnell, A. L. (2009). Adolescents' attitudes and opinions about depression treatment. Community Mental Health Journal, 46(3), 242-251. https://doi.org/10.1007/s10597$\underline{009-9224-5}$

Bradt, J., Potvin, N., Kesslick, A., Shim, M., Radl, D., Schriver, E., Gracely, E. J., \& Komarnicky-Kocher, L. T. (2014). The impact of music therapy versus music medicine on psychological outcomes and pain in cancer patients: a mixed methods study. Supportive Care in Cancer, 23(5), 1261-1271.

https://doi.org/10.1007/s00520-014-2478-7

Brumariu, L. E., \& Kerns, K. A. (2010). Parent-child attachment and internalizing symptoms in childhood and adolescence: A review of empirical findings and future directions. [Abstract] Development and Psychopathology, 22(1), 177-203. https://doi.org/10.1017/S0954579409990344

Carr, C. E., O’ Kelly, J., Sandford, S., \& Priebe, S. (2017). Feasibility and acceptability of group music therapy vs wait-list control for treatment of patients with long-term depression (the SYNCHRONY trial): Study protocol for a randomised controlled trial. [Abstract] Trials, 18(1), 149. https://doi.org/10.1186/s13063-017-1893-8

Castillo-Pérez, S., Gómez-Pérez, V., Calvillo, M., Velasco, Pérez-Campos, E., \& Mayoral, M. (2010). Effects of music therapy on depression compared with psychotherapy. The Arts in Psychotherapy, 37(5), 387-390. https://doi.org/10.1016/j.aip.2010.07.001

Chang, M.-Y., Chen, C.-H., \& Huang, K.-F. (2008). Effects of music therapy on psychological health of women during pregnancy. Journal of Clinical Nursing, 17(19), 2580-2587. https://doi.org/10.1111/j.13652702.2007.02064.X

Chen, X. (1992). Active music therapy for senile depression. [Abstract] Chinese Journal of Neurology and Psychiatry, 25(4), 208-210. https://pubmed.ncbi.nlm.nih.gov/1478135/ 
Chen, X.-J., Hannibal, N., \& Gold, C. (2015). Randomized trial of group music therapy with chinese prisoners. [Abstract] International Journal of Offender Therapy and Comparative Criminology, 60(9), 1064-1081. https://doi.org/10.1177/0306624x15572795

Choi, A.-N., Lee, M. S., \& Lee, J.-S. (2010). Group music intervention reduces aggression and improves self-esteem in children with highly aggressive behavior: A pilot controlled trial. Evidence-Based Complementary and Alternative Medicine, 7(2), 213-217. https://doi.org/10.1093/ecam/nem182

Chu, H., Yang, C. Y., Lin, Y., Ou, K. L., Lee, T. Y., O'Brien, A. P., \& Chou, K. R. (2014). The impact of group music therapy on depression and cognition in elderly persons with dementia: A randomized controlled study. [Abstract] Biological Research for Nursing, 16(2), 209-217. https://doi.org/10.1177/1099800413485410

Cook, S. C., Schwartz, A. C., \& Kaslow, N. J. (2017). Evidence-based psychotherapy: advantages and challenges. [Abstract] Neurotherapeutics, 14(3), 537-545. https://doi.org/10.1007/s13311-017-0549-4

Council on Communications and Media. (2009). Impact of music, music lyrics, and music videos on children and youth. Pediatrics, 124(5), 1488-1494. https://doi.org/10.1542/peds.2009-2145

Curtin, S. C. (2020, September 11). State suicide rates among adolescents and young adults aged 10-24: United States, 2000-2018. National Vital Statistics Reports, 69(11). https://www.cdc.gov/nchs/data/nvsr/nvsr69/nvsr-69-11-508.pdf

Dere-Meyer, C., Bender, B., Metzl, E., \& Diaz, K. (2011). Psychotropic medication and art therapy: Overview of literature and clinical considerations. The Arts in Psychotherapy, 38(1), 29-35. https://doi.org/10.1016/j.aip.2010.10.003

Dong, M., Liang-Nan Zeng, Lu, L., Xiao-Hong, L., Ungvari, G. S., Ng, C. H., Chow, I. H. I., Zhang, L., Zhou, Y., \& Yu-Tao, X. (2019). Prevalence of suicide attempt in individuals with major depressive disorder: a metaanalysis of observational surveys. Psychological Medicine, 49(10), 1691-1704. http://dx.doi.org/10.1017/S0033291718002301

Dunn, V., \& Goodyer, I. M. (2006). Longitudinal investigation into childhood-and adolescence-onset depression: Psychiatric outcome in early adulthood. British Journal of Psychiatry, 188(3), 216-222. https://doi.org/10.1192/bjp.188.3.216

Eren, B. (2015). The use of music interventions to improve social skills in adolescents with autism spectrum disorders in integrated group music therapy sessions. Procedia - Social and Behavioral Sciences, 197, 207213. https://doi.org/10.1016/j.sbspro.2015.07.125

Erkkilä, J., Punkanen, M., Fachner, J., Ala-Ruona, E., Pöntiö, I., Tervaniemi, M., Vanhala, M., \& Gold, C. (2011). Individual music therapy for depression: randomised controlled trial. The British Journal of Psychiatry: The Journal of Mental Science, 199(2), 132-139. https://doi.org/10.1192/bjp.bp.110.085431

Feng, F., Zhang, Y., Hou, J., Cai, J., Jiang, Q., Li, X., Zhao, Q., \& Li, B.-an. (2018). Can music improve sleep quality in adults with primary insomnia? A systematic review and network meta-analysis. [Abstract] International Journal of Nursing Studies, 77, 189-196. https://doi.org/10.1016/j.ijnurstu.2017.10.011 
Field, T., Martinez, A., Nawrocki, T., Pickens, J., Fox, N. A., \& Schanberg, S. (1998). Music shifts frontal EEG in depressed adolescents. Adolescence, 33(129), 109-116. https://pubmed.ncbi.nlm.nih.gov/9583665/

Geipel, J., Koenig, J., Hillecke, T. K., Resch, F., \& Kaess, M. (2018). Music-based interventions to reduce internalizing symptoms in children and adolescents: A meta-analysis. Journal of Affective Disorders, 225 , 647-656. https://doi.org/10.1016/j.jad.2017.08.035

Ghasemtabar, S. N., Hosseini, M., Fayyaz, I., Arab, S., Naghashian, H., \& Poudineh, Z. (2015). Music therapy: An effective approach in improving social skills of children with autism. Advanced Biomedical Research, 4, 157. https://doi.org/10.4103/2277-9175.161584

Gold, C., Erkkilä, J., Bonde, L. O., Trondalen, G., Maratos, A., \& Crawford, M. J. (2011). Music therapy or music medicine? Psychotherapy and Psychosomatics, 80(5), 304-304. https://doi.org/10.1159/000323166

Gold, C., Mössler, K., Grocke, D., Heldal, T. O., Tjemsland, L., Aarre, T., Aarø, L. E., Rittmannsberger, H., Stige, B., Assmus, J., \& Rolvsjord, R. (2013). Individual music therapy for mental health care clients with low therapy motivation: Multicentre randomised controlled trial. [Abstract] Psychotherapy and Psychosomatics, 82(5), 319-331. https://doi.org/10.1159/000348452

Gutgsell, K. J., Schluchter, M., Margevicius, S., DeGolia, P. A., McLaughlin, B., Harris, M., Mecklenburg, J., \& Wiencek, C. (2013). Music therapy reduces pain in palliative care patients: a randomized controlled trial. Journal of Pain and Symptom Management, 45(5), 822-831. https://doi.org/10.1016/j.jpainsymman.2012.05.008

Hakvoort, L., Bogaerts, S., Thaut, M. H., \& Spreen, M. (2013). Influence of music therapy on coping skills and anger management in forensic psychiatric patients. [Abstract] International Journal of Offender Therapy and Comparative Criminology, 59(8), 810-836. https://doi.org/10.1177/0306624x13516787

Halverson-Ramos, F., Breyfogle, S., Brinkman, T., Hannan, A., Hyatt, C., Horowitz, S., Martin, T., Masko, M., Newman, J., \& Sehr, A. (2019). Music therapy in child and adolescent behavioral health. https://www.musictherapy.org/assets/1/7/MT Child Adolescent Behavioral Health 2019.pdf

Hamid, N., \& Biat, A. (2019). The effectiveness of music therapy on depression and happiness of depressed women. NeuroQuantology, 17(12), 19-26. http://dx.doi.org/10.14704/nq.2019.17.12.NQ19110

Hanser, S.B., \& Thompson L.W. (1994). Effects of a music therapy strategy on depressed older adults. The Journals of Gerontology, 49(6), 265-269. https://doi.org/10.1093/geronj/49.6.p265

Harmat, L., Takács, J., \& Bódizs, R. (2008). Music improves sleep quality in students. [Abstract] Journal of Advanced Nursing, 62(3), 327-335. https://doi.org/10.1111/j.1365-2648.2008.04602.x

Hendricks, C. B., Robinson, B., Bradley, L. J., \& Davis, K. (1999). Using music techniques to treat adolescent depression. The Journal of Humanistic Counseling, 38(1), 39. https://doi.org/10.1002/j.2164490X.1999.tb00160.x

Hendricks, C. B. (2001). A study of the use of music therapy techniques in a group for the treatment of adolescent depression [Unpublished doctoral dissertation] Texas Tech University. 
Hilliard, R. E. (2007). The effects of off-based music therapy and social work groups on childhood grief symptoms and behaviors. Journal of Music Therapy, 44(2), 123-38. https://doi.org/10.1093/jmt/44.2.123

Hwang, E.-Y., \& Oh, S.-H. (2013). A comparison of the effects of music therapy interventions on depression, anxiety, anger, and stress on alcohol-dependent clients: A pilot study. [Abstract] Music and Medicine, 5(3), 136-144. https://doi.org/10.1177/1943862113495894

Jasemi, M., Aazami, S., \& Zabihi, R. E. (2016). The effects of music therapy on anxiety and depression of cancer patients. Indian Journal of Palliative Care, 22(4), 455-458. https://doi.org/10.4103/0973-1075.191823

Jespersen, K. V., Koenig, J., Jennum, P., \& Vuust, P. (2015). Music for insomnia in adults. [Abstract] Cochrane Database of Systematic Reviews. https://doi.org/10.1002/14651858.cd010459.pub2

Kamioka, H., Mutoh, Y., Tsutani, K., Yamada, M., Park, H., Okuizumi, H., Tsuruoka, K., Honda, T., Okada, S., Park, S.-J., Kityuguchi, J., Abe, T., Handa, S., \& Oshio, T. (2014). Effectiveness of music therapy: a summary of systematic reviews based on randomized controlled trials of music interventions. Patient Preference and Adherence, 727. https://doi.org/10.2147/ppa.s61340

Khyzhna, O., \& Shafranska, K. (2020). Music therapy as an important element in shaping communication competences in children with autism spectrum disorder. Journal of History, Culture \& Art Research / Tarih Kültür ve Sanat Arastirmalari Dergisi, 9(3), 106-114. https://doi.org/10.7596/taksad.v9i3.2823

Koelsch S. (2010). Towards a neural basis of music-evoked emotions. Trends in Cognitive Sciences, 14(3), 131137. https://doi.org/10.1016/j.tics.2010.01.002

Koelsch, S. (2014). Brain correlates of music-evoked emotions. Nature Reviews Neuroscience, 15, $170-180$. https://doi.org/10.1038/nrn3666

Kwok, S. (2018). Integrating positive psychology and elements of music therapy to alleviate adolescent anxiety. Research on Social Work Practice, 29(6). https://doi.org/10.1177/1049731518773423

Langhammer, B., Sagbakken, M., Kvaal, K., Ulstein, I., Nåden, D., \& Rognstad, M. K. (2019). Music therapy and physical activity to ease anxiety, restlessness, irritability, and aggression in individuals with dementia with signs of frontotemporal lobe degeneration. Journal of Psychosocial Nursing and Mental Health Services, 57(5), 29-37. https://doi.org/10.3928/02793695-20190124-02

Leggieri, M., Thaut, M. H., Fornazzari, L., Schweizer, T. A., Barfett, J., Munoz, D. G., \& Fischer, C. E. (2019). Music intervention approaches for Alzheimer's disease: a review of the literature. Frontiers in Neuroscience, 13. https://doi.org/10.3389/fnins.2019.00132

Leichsenring, F., Hiller, W., Weissberg, M., \& Leibing, E. (2006). Cognitive-behavioral therapy and psychodynamic psychotherapy: techniques, efficacy, and indications. American Journal of Psychotherapy, 60(3), 233-259. https://doi.org/10.1176/appi.psychotherapy.2006.60.3.233 
Lejonclou, A., \& Trondalen, G. (2009). "I've started to move into my own body": Music therapy with women suffering from eating disorders. Nordic Journal of Music Therapy, 18(1), 79-92. https://doi.org/10.1080/08098130802610924

Leubner, D., \& Hinterberger, T. (2017). Reviewing the effectiveness of music interventions in treating depression. Frontiers in Psychology, 8. https://doi.org/10.3389/fpsyg.2017.01109

Levin, Y. (1998). "Brain music" in the treatment of patients with insomnia. [Abstract] Neuroscience and Behavioral Physiology, 28(3), 330-335. https://doi.org/10.1007/bf02462965

Lim, K.-B., Kim, Y.-K., Lee, H.-J., Yoo, J., Hwang, J. Y., Kim, J.-A., \& Kim, S.-K. (2013). The therapeutic effect of neurologic music therapy and speech language therapy in post-stroke aphasic patients. Annals of Rehabilitation Medicine, 37(4), 556. https://doi.org/10.5535/arm.2013.37.4.556

Mahdipour, R., \& Nematollahi, M. (2012). The effect of the music listening and the intensive care unit visit program on the anxiety, stress and depression levels of the heart surgery patients candidates. Iran Journal of Critical Care Nursing, 5(3), 133-138. http://jccnursing.com/article-1-225-en.pdf

Maj, M. (2011). When does depression become a mental disorder? British Journal of Psychiatry, 199(2), 85-86. https://doi.org/10.1192/bjp.bp.110.089094

Maratos, A., Crawford, M. J., \& Procter, S. (2011). Music therapy for depression: it seems to work, but how? British Journal of Psychiatry, 199(2), 92-93. https://doi.org/10.1192/bjp.bp.110.087494

March, J. S., Silva, S., Petrycki, S., Curry, J., Wells, K., Fairbank, J., Burns, B., Domino, M., McNulty, S., Vitiello, B., \& Severe, J. (2007). The treatment for adolescents with depression study (TADS): Long-term effectiveness and safety outcomes. Archives of General Psychiatry, 64(10), 1132-1143. https://doi.org/10.1001/archpsyc.64.10.1132

Matthews, S. (2015). Dementia and the power of music therapy. Bioethics, 29(8), 573-579. https://doi.org/10.1111/bioe.12148

Mayo Clinic Staff. (2018). Depression (major depressive disorder). Mayo Clinic. Retrieved 5 August, 2021. https://www.mayoclinic.org/diseases-conditions/depression/diagnosis-treatment/drc-20356013

McFerran, K. (2010). Adolescents, music and music therapy methods and techniques for clinicians, educators and students. Jessica Kingsley Publishers.

Meymandi A. (2009). Music, medicine, healing, and the genome project. Psychiatry , 6(9), 43-45. https://www.ncbi.nlm.nih.gov/pmc/articles/PMC2766288/

Mohammadi, A. Z., Shahabi, T., \& Panah, F. M. (2011). An evaluation of the effect of group music therapy on stress, anxiety, and depression levels in nursing home residents. Canadian Journal of Music Therapy, 17(1), $55-68$.

Mojtabai, R., Olfson, M., \& Han, B. (2016). National trends in the prevalence and treatment of depression in adolescents and young adults. Pediatrics, 138(6). https://doi.org/10.1542/peds.2016-1878 
Moncrieff, J., \& Kirsch, I. (2005). Efficacy of antidepressants in adults. BMJ, 331(7509), 155-157. https://doi.org/10.1136/bmj.331.7509.155

National Health Service. (2018, August 16). Overview - antidepressants. NHS. https://www.nhs.uk/mentalhealth/talking-therapies-medicine-treatments/medicines-and-psychiatry/antidepressants/overview/

National Institute of Mental Health. (2016). Mental health medications. https://www.nimh.nih.gov/health/topics/mental-health-medications/

National Institute of Mental Health. (2018, February). Depression. https://www.nimh.nih.gov/health/topics/depression/

National Institute of Mental Health. (2019, February). Major depression. https://www.nimh.nih.gov/health/statistics/major-depression

Naylor, K. T., Kingsnorth, S., Lamont, A., McKeever, P., \& Macarthur, C. (2011). The effectiveness of music in pediatric healthcare: a systematic review of randomized controlled trials. Evidence-based Complementary and Alternative Medicine, 2011, Article ID 464759. https://doi.org/10.1155/2011/464759

Parquet, S. C. (2017). Effects of music therapy on depressed adolescents. (Publication No. 10634904) [Doctoral dissertation, Brandman University] Proquest Dissertations and Theses.

Pasiali, V., Hassall, J., Park, H. A., \& Quick, D. (2020). Music therapy programming for persons with eating disorders. Voices: A World Forum for Music Therapy, 20(3), 15. https://doi.org/10.15845/voices.v20i3.2785

Pigott, H. E., Leventhal, A. M., Alter, G. S., \& Boren, J. J. (2010). Efficacy and effectiveness of antidepressants: current status of research. Psychotherapy and Psychosomatics, 79(5), 267-279. https://doi.org/10.1159/000318293

Popa, L. (2015). The use of music therapy as a factor of sustainable development. Procedia Economics and Finance, 32, 1060-1065. https://doi.org/10.1016/s2212-5671(15)01568-3

Porter, S., McConnell, T., McLaughlin, K., Lynn, F., Cardwell, C., Braiden, H., Boylan, J., \& Holmes, V. (2017). Music therapy for children and adolescents with behavioural and emotional problems: a randomised controlled trial. Journal of Child Psychology and Psychiatry, 58(5), 586-594. https://doi.org/10.1111/jcpp.12656

Prakash, R. (n.d.). Passive and active music therapy. Retrieved 5 August, 2021, from https://sites.duke.edu/voicestogether/series-the-potential-power-of-music-therapy-within-the-autismcommunity/passive-and-active-music-therapy/

Radulovic, R. (1996). The using of music therapy in treatment of depressive disorders. [Abstract] Summary of Master Thesis. Belgrade: Faculty of Medicine University of Belgrade.

Rafieyan, R., \& Ries, R. (2007). A description of the use of music therapy in consultation-liaison psychiatry. Psychiatry 4(1), 47-52. 
https://www.ncbi.nlm.nih.gov/pmc/articles/PMC2922391/\#: :text=Therapists\%20conduct\%20ongoing\%20as sessments $\% 20$ through,in $\% 20$ spontaneous $\% 20$ music $\% 2$ Dmaking $\% 20$ experiences.\&text=Thus $\% 2 \mathrm{C} \% 20 \mathrm{a} \% 20$ patient $\% 20$ may $\% 20$ progress,to $\% 20$ sing $\% 20$ or $\% 20$ actually $\% 20$ singing

Raglio, A., Attardo, L., Gontero, G., Rollino, S., Groppo, E., \& Granieri, E. (2015). Effects of music and music therapy on mood in neurological patients. World Journal of Psychiatry, 5(1), 68-78. https://doi.org/10.5498/wjp.v5.i1.68

Rahmani, M., Saeed, B. B., \& Aghili, M. (2016). Integrating effect of art and music therapy on depression in adolescents. Journal of Educational Sciences \& Psychology, 6(2), 78-87.

Ramirez, R., Planas, J., Escude, N., Mercade, J., \& Farriols, C. (2018). EEG-based analysis of the emotional effect of music therapy on palliative care cancer patients. Frontiers in Psychology, 9. https://doi.org/10.3389/fpsyg.2018.00254

Reangsing, C., Punsuwun, S., \& Schneider, J. K. (2021). Effects of mindfulness interventions on depressive symptoms in adolescents: A meta-analysis. International Journal of Nursing Studies, 115, 103848. https://doi.org/10.1016/j.ijnurstu.2020.103848

Romo, R., \& Gifford, L. (2007). A cost-benefit analysis of music therapy in a home hospice. [Abstract] Nursing Economics, 25(6), 353-358. https://pubmed.ncbi.nlm.nih.gov/18240837/\#: :text=In $\% 20$ this $\% 20$ small $\% 20$ study $\% 2 \mathrm{C} \% 20$ the,cost $\% 20$ bene fit $\% 20$ ratio $\% 20$ is $\% 200.95$

Sharma, M., \& Jagdev, T. (2012). Use of music therapy for enhancing self-esteem among academically stressed adolescents. Pakistan Journal of Psychological Research, 27(1), 53-64.

Shiranibidabadi, S., \& Mehryar, A. (2015). Music therapy as an adjunct to standard treatment for obsessive compulsive disorder and co-morbid anxiety and depression: A randomized clinical trial. [abstract] Journal of Affective Disorders, 184, 13-17. https://doi.org/10.1016/j.jad.2015.04.011

Shuman, J., Kennedy, H., DeWitt, P., Edelblute, A., \& Wamboldt, M. Z. (2016). Group music therapy impacts mood states of adolescents in a psychiatric hospital setting. [Abstract] The Arts in Psychotherapy, 49, 50-56. https://doi.org/10.1016/j.aip.2016.05.014

Statista Research Department (2021, January 8). Favorite music genres among consumers in the United States as of July 2018, by age group. https://www.statista.com/statistics/253915/favorite-music-genres-in-the-us/

Stegemann, T., Geretsegger, M., Phan Quoc, E., Riedl, H., \& Smetana, M. (2019). Music therapy and other musicbased interventions in pediatric health care: An overview. Medicines), 6(1), 25. https://doi.org/10.3390/medicines6010025

Swanson, A. L. (2020). Music therapy in schools: Stimulating the mind and body to create positive change. [Abstract] Promoting Mind-Body Health in Schools: Interventions for Mental Health Professionals. 233244. https://doi.org/10.1037/0000157-016 
Tang, Q., Huang, Z., Zhou, H., \& Ye, P. (2020). Effects of music therapy on depression: A meta-analysis of randomized controlled trials. PlOS ONE, 15(11), e0240862. https://doi.org/10.1371/journal.pone.0240862

Tervo, J. (2001). Music therapy for adolescents. Clinical Child Psychology and Psychiatry, 6(1), 79-91. https://citeseerx.ist.psu.edu/viewdoc/download?doi=10.1.1.612.7940\&rep=rep1\&type $=$ pdf

Thaut, M. H., Gardiner, J. C., Holmberg, D., Horwitz, J., Kent, L., Andrews, G., Donelan, B., \& McIntosh, G. R. (2009). Neurologic music therapy improves executive function and emotional adjustment in traumatic brain injury rehabilitation. [Special Issue]. Annals of the New York Academy of Sciences, 1169, 406-416. https://doi.org/10.1111/j.1749-6632.2009.04585.x

Twenge, J. M. (2020). Increases in depression, self-harm, and suicide among U.S. adolescents after 2012 and links to technology use: Possible mechanisms. Psychiatric Research and Clinical Practice, 2(1), 19-25. https://doi.org/10.1176/appi.prcp.20190015

Wakim, J. H., Smith, S., \& Guinn, C. (2010). The efficacy of music therapy. Journal of PeriAnesthesia Nursing, 25(4), 226-232. https://doi.org/10.1016/j.jopan.2010.05.009

Wang, C.-F., Sun, Y.-L., \& Zang, H.-X. (2014). Music therapy improves sleep quality in acute and chronic sleep disorders: A meta-analysis of 10 randomized studies. International Journal of Nursing Studies, 51(1), 51-62. https://doi.org/10.1016/j.ijnurstu.2013.03.008

Weinberger, A., Martinez, A., Nash, D., Gbedemah, M., \& Galea, S. (2017, October 30). Depression is on the rise in the U.S., especially among young teens. Columbia University Mailman School of Public Health. https://www.publichealth.columbia.edu/public-health-now/news/depression-rise-us-especially-among-young$\underline{\text { teens }}$

Wheeler, B. L., Shiflett, S. C., \& Nayak, S. (2003). Effects of number of sessions and group or individual music therapy on the mood and behavior of people who have had strokes or traumatic brain injuries. Nordic Journal of Music Therapy, 12(2), 139-151. https://doi.org/10.1080/08098130309478084

Wisdom, J. P., Clarke, G. N., \& Green, C. A. (2006). What teens want: barriers to seeking care for depression. Administration and Policy in Mental Health and Mental Health Services Research, 33(2), 133-145. https://doi.org/10.1007/s10488-006-0036-4

Wu, S. M. (2002). Effects of music therapy on anxiety, depression, and self-esteem of undergraduates. [Abstract] Psychologia, 45(2), 104-114. https://doi.org/10.2117/psysoc.2002.104

Zanders, M. L. (2018). Music as therapy versus music in therapy. Journal of Neuroscience Nursing, 50(4), $218-219$. https://doi.org/10.1097/jnn.0000000000000379

Zerhusen, J. D., Boyle, K., \& Wilson, W. (1991). Out of the darkness: group cognitive therapy for depressed elderly. Journal of Psychosocial Nursing and Mental Health Services, 29(9), 16-21.

https://pubmed.ncbi.nlm.nih.gov/1941727/ 
Zhao, K., Bai, Z. G., Bo, A., \& Chi, I. (2016). A systematic review and meta-analysis of music therapy for the older adults with depression. International Journal of Geriatric Psychiatry, 31(11), 1188-1198.

https://doi.org/10.1002/gps.4494 